\title{
PENGARUH BRAND IMAGE DAN SERVICE QUALITY \\ TERHADAP KEPUASAN PELANGGAN, SERTA IMPLIKASINYA PADA WORD OF MOUTH STUDI KASUS PADA UNIVERSITAS MERCU BUANA JAKARTA
}

\author{
Sugeng Lubar Prastowo \\ sg.lubar@unis.ac.id
}

Program Studi Manajemen Universitas Islam Syekh Yusuf (UNIS) Tangerang

\begin{abstract}
The condition of the number of universities that very much as well as the changing demands of consumers and potential consumers of the attributes and performance of educational services that they get trigger increased intensity of competition among service providers colleges. Evident of instability number ratio of new admissions process at UMB. This study aims to examine and analyze the effect of brand image, service quality to customer satisfaction as well as its implications on word of mouth at the University of Mercu Buanan Jakarta. The research data is taken from the questionnaire data of 100 students, the results of the calculation formula of slovin with error or error rate of $10 \%=$ 0. The sampling method that has been used is convenience sampling of 6947 the population of regular students at UMB. The analysis method that has been used in this research is the Structural Equation Modeling (SEM). Research shows that brand image, service quality and customer satisfaction significantly influence word of mouth. Partially showed that the brand image factors certainly has a positive and significant impact on customer satisfaction, service quality factors are also has a positive and significant impact on customer satisfaction, and customer satisfication factor also has a positive and significant impact on word of mouth. Service quality is the most powerful variable influence on customer satisfaction in Mercu Buana University.
\end{abstract}

Keywords : Brand Image, Service Quality, Customer Satisfaction, Word of Mouth

\begin{abstract}
ABSTRAK
Kondisi jumlah perguruan tinggi yang sangat banyak serta perubahan tuntutan konsumen dan calon konsumen terhadap atribut dan kinerja jasa pendidikan yang mereka dapatkan memicu meningkatnya intensitas persaingan antar penyedia jasa perguruan tinggi. Terbukti dari tidak stabilnya angka ratio dari proses penerimaan mahasiswa baru di UMB. Penelitian ini bertujuan untuk menguji dan menganalisis pengaruh brand image, sevice quality, terhadap kepuasan pelanggan serta implikasinya pada word of mouth di Universitas Mercu Buanan Jakarta. Data penelitian merupakan data kuisioner yang diambil dari 100 mahasiswa, hasil dari perhitungan rumus slovin dengan tingkat kesalahan atau eror $10 \%=0.1$. Metode sampling yang digunakan adalah convenience sampling dari 6947 jumlah populasi mahasiswa reguler di UMB. Metode analisis yang digunakan dalam penelitian ini adalah The Structural Equation Modelling (SEM). Hasil Penelitian menunjukan bahwa brand image, service quality, dan kepuasan pelanggan, berpengaruh secara signifikan terhadap word of mouth. Secara parsial menunjukan bahwa faktor brand image pasti berpengaruh positif dan signifikan terhadap kepuasan pelanggan, faktor service
\end{abstract}


quality juga berpengaruh positif dan signifikan terhadap kepuasan pelanggan, dan faktor kepuasan pelanggan berpengaruh positif dan signifikan terhadap word of mouth. Service quality merupakan variabel yang paling kuat pengaruhnya terhadap kepuasan pelanggan di Universitas Mercu Buana Jakarta.

Kata kunci : brand image, service quality, kepuasan pelanggan, word of mouth

\section{PENDAHULUAN}

Saat ini banyak berdirinya perguruan-perguruan tinggi baru, memberikan fenomena baru dalam pendidikan. Pendidikan semakin berkembang dan kompleks baik dari bentuk maupun pendekatan pendidikan. Secara objektif, masyarakat terkadang dibingungkan untuk menentukan pilihan perguruan tinggi yang akan digunakan. Oleh karena itu persaingan dalam pendidikan tinggi cukup diperhatikan karena ini dapat berdampak pada reputasi dan jumlah mahasiswa baru yang masuk dalam tiap tahunnya.

Tabel 1.1. Ratio Penerimaan Seleksi Mahasiswa Baru

\begin{tabular}{|c|c|c|c|c|}
\hline Tahun & \multicolumn{3}{|c|}{ Jumlah } & \multirow{2}{*}{ Ratio } \\
\cline { 1 - 3 } Akademik & $\begin{array}{c}\text { Peserta } \\
\text { Tes }\end{array}$ & Lulus/ Diterima & $\begin{array}{c}\text { Daftar } \\
\text { Ulang }\end{array}$ & 2242 \\
\hline $2009 / 2010$ & 3468 & 2363 & 1828 & 0,949 \\
\hline $2010 / 2011$ & 2885 & 2027 & 1920 & 0,902 \\
\hline $2011 / 2012$ & 2927 & 2002 & 1997 & 0,898 \\
\hline $2012 / 2013$ & 3269 & 2224 & 2416 & 0,913 \\
\hline $2013 / 2014$ & 3802 & 2646 & & \\
\hline
\end{tabular}

Sumber : Marketing Universitas Mercu Buana 2014

Telah terjadi naik turunnya peminat dalam proses penerimaan mahasiswa baru di UMB. Ini berkaitan dengan media pemasaran yang dilakukan oleh perguruan tinggi yang merupakan sebuah kegiatan edukasi, menginformasikan, dan mengingatkan secara terusmenerus akan fiture dan benefit suatu produk, sehingga konsumen memilih produk tersebut.

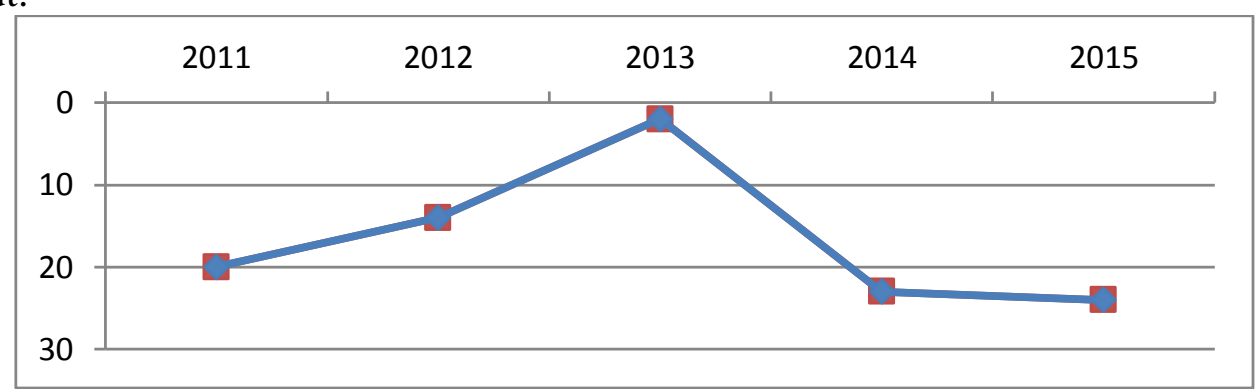

Gambar 1.1. Peringkat Webometrics Universitas Mercu Buana

Sumber : http://www.webometrics.info/en/asia/indonesia\%20 (Juni 2015)

Ini terkait dengan sudut pandang masyarakat mengenai penggambaran universitas tersebut. Di buktikan dengan peringkat webometrics yang diraih universitas mercu buana Juni 2015 pada peringkat ke 24 yang membuat mercu buana menurun dari prestasi sebelumnya.

Seiring dengan mendapatkannya sertifikasi ISO 9001-2008 pada tahun 2010 universitas mercu buana terus berupaya menjadikan perguruan tinggi yang berkualitas dengan mengutamakan kepuasan pelanggan. Terbukti dengan membentuk unit customer care, yang menangani dan mengatasi segala keluhan pelanggan. Berikut data keluhan yang terjadi di UMB terutama mahasiswa yang sedang menjalankan pendidikannya. 
Tabel 1.2. Laporan Pengaduan Keluhan Mahasiswa

\begin{tabular}{|l|c|}
\hline \multicolumn{1}{|c|}{ Jenis Komplain } & Jumlah \\
\hline Pelayanan Akademik & 39 \\
\hline Fasilitas Kampus \& Ruang Kuliah & 16 \\
\hline Staff Pengajar (Dosen) & 15 \\
\hline Pengisian KRS & 7 \\
\hline Pelayanan Keuangan & 7 \\
\hline Pelayanan Kemahasiswaan & 6 \\
\hline Jadwal Kuliah \& Ujian & 6 \\
\hline
\end{tabular}

Sumber : Humas UMB 2014

Service quality yang baik, akan memberikan manfaat kepada lembaga pendidikan karena mahasiswa merasa terpenuhi kebutuhan dan keinginannya, sehingga mahasiswa akan merasa puas dari produk jasa pendidikan yang mereka terima. Ini dibuktikan pada tabel 1.2 dengan tingkat keluhan pelayanan akademik yang tinggi, menciptakan kritik dalam memperoleh pelayanan yang ada. Berikut data hasil prestudi yang dilakukan untuk mengukur tingkat kepuasan pada 35 mahasiswa UMB.

Tabel 1.3. Prestudi Kepuasan Mahasiswa

\begin{tabular}{|c|l|c|}
\hline \multirow{2}{*}{ No } & \multicolumn{1}{|c|}{ Kepuasan } & \multirow{2}{*}{ Kolom Pernyataan } \\
\cline { 2 - 3 } & \multicolumn{1}{|c|}{} \\
\hline 1 & Kinerja pelayanan UMB sesuai dengan harapan saya. & $25.8 \%$ \\
\hline 2 & Saya puas dengan sistem proses akademik di UMB yang mudah. & $27.3 \%$ \\
\hline 3 & Saya puas dengan keputusan kuliah di UMB. & $42.3 \%$ \\
\hline
\end{tabular}

Sumber : Data Prestudi Penelitian 2015

Pengambilan keputusan untuk memilih suatu produk, sering melibatkan unsur kepercayaan dan kejujuran, yang biasanya lebih dipengaruhi oleh orang-orang dekat, seperti teman atau saudara. Namun, terdapat word of mouth negatif yang timbul dalam media massa dua tahun belakangan terakhir di UMB. Bisa berdampak pada cerita negatif, penurunan citra kampus, dan proses penerimaan mahasiswa baru.

Tabel 1.4. Word Of Mouth Negatif Di Media Massa

\begin{tabular}{|c|l|c|c|}
\hline No & \multicolumn{1}{|c|}{ Tag Line Berita } & \multicolumn{1}{|c|}{$\begin{array}{c}\text { Tanggal } \\
\text { Terbit }\end{array}$} \\
\hline 1 & Dibelai Wakil Dekan, Mahasiswi Mercu Buana 'Shock' Berat & Liputan6.com & $2-12-2013$ \\
\hline 2 & $\begin{array}{l}\text { Raba- raba Mahasiswi, Pejabat Dekanat Universitas Mercu } \\
\text { Buana Dipecat }\end{array}$ & Detik.com & $2-12-2013$ \\
\hline 3 & Dosen Mercu Buana gerayangi tubuh mahasiswi didalam mobil & Merdeka.com & $3-12-2013$ \\
\hline 4 & 8 Mahasiswa diamakan Polisi Saat Demo Tolak BBM Naik & Okezone.com & $3-12-2014$ \\
\hline & $\begin{array}{l}\text { Gara- Gara Kursi, Mahasiwa Mercu Buana Ditusuk Teman } \\
\text { Sendiri }\end{array}$ & \multicolumn{1}{|c|}{ Viva.co.id } & $21-5-2015$ \\
\hline 6 & Mahasiswa Mercu Buana Tusuk Temannya Sendiri & Koransindo.com & $21-5-2015$ \\
\hline
\end{tabular}

Sumber: Berbagai Literatur 2015

Word of mouth sangat penting pada bidang pendidikan, hal ini berkaitan dengan peranannya sebagai industri jasa. Oleh karena itu, mengevaluasi anggapan mahasiswa terhadap kepuasan mereka yang bisa menciptakan word of mouth, diharapkan terus dilakukan oleh universitas, sekolah tinggi, institut sebagai lembaga pendidikan tinggi.

\section{KAJIAN PUSTAKA}

Brand Image Menurut Tjiptono (2006:27), menciptakan sebuah brand adalah ketika seorang pemasar membuat nama, logo atau simbol baru untuk jenis usahanya. Brand atau merek menjadi pengenal bagi penjual atau pembuat suatu produk atau jasa. Menurut Sopiah \& Syihabudhin (2008:138) image adalah suatu bayangan atau gambaran yang ada di dalam benak seseorang yang timbul karena emosi dan reaksi terhadap lingkungan 
sekitarnya. Sedangkan faktor-faktor pendukung terbentuknya brand image dalam keterkaitannya dengan asosiasi merek menurut Kotler \& Keller (2009:336) adalah 1) Favorability of brand association atau keunggulan asosiasi merek, salah satu faktor pembentuk brand image adalah keunggulan bersaing suatu produk atau competitive advantage. 2) Strength of brand association atau kekuatan asosiasi merek, Ditengah maraknya persaingan brand suatu produk tetap lebih mudah dikenal dan terjaga. 3) Uniquesness of brand association atau keunikan suatu merek, yang merupakan pembeda dari suatu produk atau merek.

Service Quality, Menurut Tjiptono (2006:224) Jasa bersifat intangible, dan merupakan hasil pengalaman pelanggan, dimana aktivitas produksi dan konsumsi berlangsung pada saat bersamaan. Kotler dan Keller (2008:136), menyatakan bahwa konsumen menciptakan harapan-harapan jasa dari pengalaman masa lalu, komunikasi word of mouth, dan iklan. Konsumen membandingkan jasa yang dipersepsikan dan yang diharapkan. Zeithhaml dalam Husein Umar (2005: 38) didalam memberikan jasa pada pelayanan jasa yang baik kepada pelanggan, terdapat lima dimensi kualitas jasa atau layanan, yaitu 1) Bukti fisik (Tangibles), 2) Keandalan (Reliability), 3) Daya tanggap (Responsiveness), 4) Jaminan (Assurance), 5) Empati (Empathy).

Kepuasan Pelanggan, Lovelock dan Wirtz (2007:102) mengartikan kepuasan adalah keadaan emosional, reaksi pasca pembelian dapat berakibat kemarahan, ketidakpuasan, kejengkelan, netralitas, gembira, atau senang. Oliver dalam Aryani dan Rosinta (2010) merumuskan, kepuasan adalah respon menyeluruh yang mempengaruhi perbedaan antara harapan dengan apa yang dirasakan setelah pelayanan tersebut dikomsumsi, atau dievaluasi purnabeli, dimana persepsi terhadap kinerja jasa yang dipilih memenuhi harapan pelanggan. Kotler \& Keller (2008: 177) menyatakan kepuasan adalah perasaan senang atau kecewa, yang muncul setelah membandingkan antara persepsi/ kesannya terhadap kinerja atau hasil suatu produk dan harapan-harapannya. Kepuasan merupakan fungsi dari persepsi/kesan atas kinerja dan harapan.

Word Of Mouth, Hawkins dkk. (2007 : 241) mengemukakan bahwa WOM merupakan kegiatan penyebaran informasi dari seseorang kepada orang lainnya dalam bentuk komunikasi verbal termasuk bertatap muka langsung, melaui telepon, dan internet. Suprapti (2010 : 274) mengemukakan bahwa komunikasi getok tular atau word of mouth merupakan komunikasi pribadi antara dua individu atau lebih, misalnya antara pelanggan atau antar anggota dari suatu kelompok. Dimensi word of mouth menurut Rosiana (2011) : 1) Cerita positif, adalah keinginan konsumen untuk mengabarkan hal-hal positif mengenai produk yang dikonsumsinya kepada orang lain. 2) Rekomendasi, adalah keinginan konsumen untuk memberikan rekomendasi kepada orang lain yang membutuhkan informasi mengenai produk yang berkualitas. 3) Ajakan, adalah kesediaan konsumen untuk mengajak orang lain agar menggunakan produk yang telah dikonsumsinya.

\section{Kerangka Pemikiran dan Hipotesis}

Kerangka Pemikiran untuk Pengaruh Brand Image, Service Quality terhadap Kepuasan Pelanggan serta Implikasinya terhadap Word Of Mouth adalah sebagai berikut :

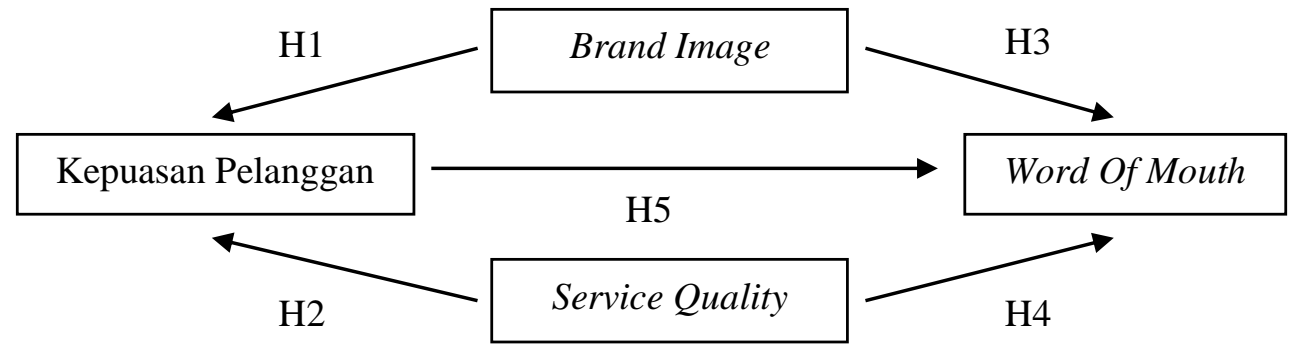




\section{Gambar 1.2. Model Penelitian}

Sumber : Berbagai Literatur (2014)

\section{Penelitian Terdahulu}

Rahim, dkk (2010) mengatakan dalam penelitiannya bahwa service quality berpengaruh secara positif terhadap kepuasan pelanggan dan membentuk loyalitas. Ini dimaksudkan jika ada kenaikan pada service quality mana terjadi pula pada kepuasan pelanggan. Harapan ini terbentuk karena service quality yang baik sehingga menciptakan loyalitas.

Penelitian Young (2012), mengatakan bahwa brand image dapat mempengaruhi kepuasan pelanggan. Untuk itu dengan brand image disertai kepuasan pelanggan sebagai nilai lebih dari perusahaan tentunya akan menguatkan word of mouth sebagai sarana komunikasi yang efektif dan efesien.

Penelitian lain mengemukakan bahwa pada saat kepuasan mengalami penurunan, maka word of mouth pun mengalami hal yang sama. Untuk itu, kepuasan menjadi penentu tetap terjaganya word of mouth dari satu orang ke orang lain( Lori, dkk.2014).

Hipotesis, Berdasarkan kerangka pemikiran tersebut, hipotesis yang akan diuji pada penelitian ini adalah :

H1 : Brand Image berpengaruh terhadap Kepuasan Mahasiswa

H2 : Service Quality berpengaruh terhadap Kepuasan Mahasiswa

H3 : Brand Image berpengaruh terhadap Word Of Mouth

H4 : Service Quality berpengaruh terhadap Word Of Mouth

H5 : Kepuasaan Mahasiswa berpengaruh terhadap Word Of Mouth

\section{METODE PENELITIAN}

Desain penelitian ini adalah penelitian deskriptif, dengan metode kuantitatif. Sebagai langkah awal, penulis merumuskan hipotesis dan rancanagan penelitian yang terstruktur, serta menggunakan sumber-sumber data survei atau kuisioner.

Populasi yang digunakan adalah Mahasiswa mercu buana sebanyak 6947 terdaftar aktif dikelas reguler yang akan dijadikan penulis sebagai media penelitian dan disebut dengan Responden.

Tabel 1.5. Data Mahasiswa Reguler 2013-2014

\begin{tabular}{|c|c|c|c|}
\hline No. & Fakultas & Jurusan / Konsentrasi & Jumlah Mahasiswa Reguler \\
\hline \multirow{3}{*}{1.} & \multirow{3}{*}{ Desain dan Seni Kreatif (FDSK) } & Desain Komunkasi Visual & 325 \\
\hline & & Disain Produk & 486 \\
\hline & & Desain Interior & 108 \\
\hline \multirow{2}{*}{2} & \multirow{2}{*}{ Ilmu Komputer } & Teknik Informatika & 421 \\
\hline & & Sistem Informasi & 577 \\
\hline \multirow{5}{*}{3} & \multirow{5}{*}{ Teknik } & Teknik Mesin & 248 \\
\hline & & Teknik Sipil & 214 \\
\hline & & Teknik Arsitektur & 224 \\
\hline & & Teknik Elektro & 104 \\
\hline & & Teknik Industri & 178 \\
\hline \multirow{4}{*}{4.} & \multirow{2}{*}{ Ekonomi } & Manajemen & 1000 \\
\hline & & Akuntansi & 889 \\
\hline & \multirow{2}{*}{ Program Diploma III } & Manajemen Perusahaan & 84 \\
\hline & & Akuntansi & 105 \\
\hline \multirow{3}{*}{5.} & \multirow{3}{*}{ Ilmu Komunikasi } & Penyiaran & 934 \\
\hline & & Hubungan Masyarakat & 486 \\
\hline & & Periklanan & 230 \\
\hline 6. & Psikologi & Psikologi & 334 \\
\hline & & Jumlah & 6947 \\
\hline
\end{tabular}

Sumber : Biro Administrasi Akademik UMB 2014 
Besarnya N (Populasi sampel) yang diambil adalah jumlah populasi mahasiswa Universitas Mercu Buana, sebesar populasi responden dan tingkat kesalahan atau nilai error yang ditetapkan adalah $10 \%$.

Perhitungan jumlah sampel, sebagai berikut : $n=\frac{N}{1+N e^{2}}$

$$
\begin{aligned}
& \mathrm{n}=6947 /\left(1+6947(0,1)^{2}\right) \\
& \mathrm{n}=6947 /(1+69.47) \\
& \mathrm{n}=6947 / 70.47 \\
& \mathrm{n}=\mathbf{9 8 , 5 8} \text { (Dibulatkan menjadi } 99 \text { responden) }
\end{aligned}
$$

Sampel yang diteliti adalah jumlah responden dari populasi yang dipilih dengan convinience sampling sebanyak 100 mahasiswa agar tidak terjadi pembiasan.

Untuk memastikan ketepatan terhadap instrumen dan data yang dipilih dalam pengambilan data, diperlukan pengujian terhadap instrumen dan data yang diperoleh dengan pengujian validitas dan realibilitas. agar instrumen yang dipakai, dan data yang diambil benar- benar valid dan reliabel.

Untuk pengembangan model dan pengujian hipotesis menggunakan The Structural Equation Modelling (SEM) dari paket software statistik AMOS versi 21.

\section{HASIL DAN PEMBAHASAN}

Responden yang dipilih dalam penelitian ini adalah 100 mahasiswa reguler Universitas Mercu Buana kampus meruya, dengan pertimbangan sebagai responden mereka telah merasakan pendidikan dan pelayanan sehingga dapat melakukan penilaian. Dengan tingkat mahasiswa pada semester 2 sebanyak 17 responden, tingkat semester 4

\begin{tabular}{|c|c|c|c|c|}
\hline No. & Fakultas & Jurusan / Konsentrasi & $\begin{array}{c}\text { Jumlah } \\
\text { Mahasiswa }\end{array}$ & $\begin{array}{c}\text { Jumlah } \\
\text { Responden }\end{array}$ \\
\hline \multirow{3}{*}{1.} & \multirow{3}{*}{$\begin{array}{l}\text { Desain dan Seni } \\
\text { Kreatif (FDSK) }\end{array}$} & Desain Komunkasi Visual & 325 & 5 \\
\hline & & Disain Produk & 486 & 7 \\
\hline & & Desain Interior & 108 & 2 \\
\hline \multirow{2}{*}{2} & \multirow{2}{*}{ Ilmu Komputer } & Teknik Informatika & 421 & 6 \\
\hline & & Sistem Informasi & 577 & 8 \\
\hline \multirow{5}{*}{3} & \multirow{5}{*}{ Teknik } & Teknik Mesin & 248 & 4 \\
\hline & & Teknik Sipil & 214 & 3 \\
\hline & & Teknik Arsitektur & 224 & 4 \\
\hline & & Teknik Elektro & 104 & 1 \\
\hline & & Teknik Industri & 178 & 3 \\
\hline \multirow{4}{*}{4.} & \multirow{2}{*}{ Ekonomi } & Manajemen & 1000 & 14 \\
\hline & & Akuntansi & 889 & 13 \\
\hline & \multirow{2}{*}{$\begin{array}{l}\text { Program Diploma } \\
\text { III }\end{array}$} & Manajemen Perusahaan & 84 & 1 \\
\hline & & Akuntansi & 105 & 1 \\
\hline \multirow{3}{*}{5.} & \multirow{3}{*}{ Ilmu Komunikasi } & Penyiaran & 934 & 13 \\
\hline & & Hubungan Masyarakat & 486 & 7 \\
\hline & & Periklanan & 230 & 3 \\
\hline 6. & Psikologi & Psikologi & 334 & 5 \\
\hline & & Jumlah & 6947 & 100 \\
\hline
\end{tabular}
sebanyak 32 responden, tingkat semeter 6 sebanyak 34 responden dan pada semester 8 sebanyak 17 responden.

\section{Tabel 1.6. Responden Penelitian}

Sumber : Hasil Pengolahan Data Penelitian (2015)

Berdasarkan data hasil itung yang ada terlihat bahwa koefisien korelasi antara masing-masing indikator terhadap skor konstruk dari setiap variabel menunjukkan hasil yang signifikan, dan menunjukkan bahwa nilai diatas 0.30. Sehingga dapat disimpulkan bahwa semua item pertanyaan dinyatakan valid. 
Tabel 1.7. Hasil Uji Validitas

\begin{tabular}{|l|l|c|c|}
\hline \multicolumn{1}{|c|}{ Variabel } & \multicolumn{1}{|c|}{ Dimensi/Indikator } & Korelasi & Keterangan \\
\hline \multirow{3}{*}{$\begin{array}{l}\text { Citra Merek (Brand Image) } \\
\text { Keller 2009 }\end{array}$} & Favorability of Brand Association & $.796^{* *}$ & Valid \\
\cline { 2 - 4 } & Strength of Brand Association & $.830^{* *}$ & Valid \\
\cline { 2 - 4 } & Uniquness of Brand Association & $.759^{* *}$ & Valid \\
\hline \multirow{3}{*}{$\begin{array}{l}\text { Kualitas Pelayanan (Service } \\
\text { Huality) Zeithhaml dalam }\end{array}$} & Bukti Fisik (Tangibles) & $.809^{* *}$ & Valid \\
\cline { 2 - 4 } & Keandalan (Reability) & $.880^{* *}$ & Valid \\
\cline { 2 - 4 } & Daya Tanggap (Responsiveness) & $.871^{* *}$ & Valid \\
\cline { 2 - 4 } & Jaminan (Assurance) & $.788^{* *}$ & Valid \\
\cline { 2 - 4 } & Empati (Empathy) & $.820^{* *}$ & Valid \\
\hline Kepuasan Pelanggan (Customer & Harapan & $.804^{* *}$ & Valid \\
\cline { 2 - 4 } Satisfaction) Kotler 2008 & Kesan & $.822^{* *}$ & Valid \\
\hline \multirow{3}{*}{ Word Of Mouth Rosiana (2011) } & Cerita positif & $.553^{* *}$ & Valid \\
\cline { 2 - 4 } & Rekomendasi & $.716^{* *}$ & Valid \\
\cline { 2 - 4 } & Ajakan & $.629^{* *}$ & Valid \\
\hline
\end{tabular}

Sumber : Hasil Pengolahan Data Penelitian (2015)

Tingkat reliabilitas yang dapat diterima adalah $\geq 0,60$ dari masing-masing variabel yang diukur, Brand Image dalam penelitian ini memiliki nilai yang lebih besar dari 0.60 yakni sebesar 0.747, variabel Service Quality dalam penelitian ini memiliki nilai yang lebih besar dari 0.60 yakni sebesar $\mathbf{0 . 8 3 3}$, Kepuasan Pelanggan dalam penelitian ini memiliki nilai yang lebih besar dari 0.60 yakni sebesar 0.662, Word Of Mouth dalam penelitian ini memiliki nilai yang lebih besar dari 0.60 yakni sebesar $\mathbf{0 . 6 2 1}$, sehingga dapat disimpulkan bahwa indikator-indikator tersebut reliable karena berada di atas minimal 0.60.

Data dengan sampel sebesar 100 responden dilakukan uji normalitas terdahulu. Data dikatakan normal apabila c.r multivariate (critical ratio) memiliki syarat $\mathbf{- 2 . 5 8}<\boldsymbol{c} . \boldsymbol{r}<$ 2.58. Hasil uji normalitas menunjukkan data tidak normal karena memiliki c.r multivariate sebesar 4.901 > 2.58, sehingga perlu dilakukan pembersihan data outlier yaitu sigifikasi p1 dan p2 < 0.05. Hasil pembersihan dari outlier 13, 57, 64, 3, 38, 54, 9, 6, 89, 45 dan 37 diperoleh c.r multivariate $\mathbf{1 . 3 2}<\mathbf{2 . 5 8}$ yang berarti data normal dari 100 data terdapat outlier sebanyak 11 data sehingga data akhir yang digunakan dalam penelitian sebesar 89 data.

Tabel 1.8. Uji normalitas setelah data dibersihkan

\begin{tabular}{cllcccc}
\hline Variable & min & max & skew & $\boldsymbol{c . r}$. & kurtosis & $\boldsymbol{c . r}$. \\
\hline X43 & 2 & 9 & $-0,235$ & $-0,906$ & $-0,925$ & $-1,78$ \\
X42 & 2 & 9 & $-0,393$ & $-1,512$ & $-0,025$ & $-0,049$ \\
X41 & 4 & 10 & 0,166 & 0,64 & 0,329 & 0,633 \\
X32 & 2 & 10 & $-0,154$ & $-0,593$ & $-0,48$ & $-0,924$ \\
X31 & 2 & 9 & $-0,117$ & $-0,449$ & $-0,749$ & $-1,443$ \\
X21 & 8 & 17 & $-0,11$ & $-0,423$ & $-1,151$ & $-2,217$ \\
X22 & 4 & 17 & $-0,068$ & $-0,263$ & $-0,692$ & $-1,333$ \\
X23 & 5 & 17 & 0,159 & 0,612 & $-0,875$ & $-1,685$ \\
X24 & 8 & 18 & 0,142 & 0,548 & $-0,712$ & $-1,372$ \\
X25 & 3 & 12 & $-0,318$ & $-1,226$ & $-0,48$ & $-0,924$ \\
X13 & 8 & 15 & 0,06 & 0,231 & $-0,027$ & $-0,052$ \\
X12 & 6 & 15 & $-0,441$ & $-1,7$ & $-0,212$ & $-0,409$ \\
X11 & 7 & 13 & $-0,407$ & $-1,567$ & $-0,437$ & $-0,842$ \\
\hline Multivariate & & & & & $\mathbf{5 , 5 3 1}$ & $\mathbf{1 , 3 2 1}$ \\
\hline
\end{tabular}

Sumber : Hasil Pengolahan Data Penelitian (2015) 
Dari hasil pengolahan data menggunakan AMOS versi 21 menunjukkan bahwa model yang direncanakan kurang fit secara marginal, karena setelah diuji kecocokkannya Nilai CMIN/ DF, AGFI, dan RMSEA kurang baik. Oleh sebab itu model tersebut kemudian dimodifikasi mengikuti modification indices.

Tabel 1.9. Modification Indices

\begin{tabular}{lllrr}
\hline & & & M.I. & Par Change \\
\hline X1BI & $<->$ & X2KL & 9,911 & 0,805 \\
e11 & $<-->$ & X1BI & 4,108 & $-0,38$ \\
e13 & $<-->$ & X1BI & 7,466 & 0,403 \\
e10 & $<-->$ & e11 & 13,784 & 0,775 \\
e9 & $<-->$ & e11 & 8,758 & 0,529 \\
e5 & $-->$ & e12 & 4,379 & $-0,638$ \\
e3 & $<-->$ & e13 & 8,263 & 0,433 \\
e2 & $<-->$ & X2KL & 5,08 & 0,709 \\
e2 & $<-->$ & e13 & 4,751 & 0,395 \\
e2 & $<-->$ & e4 & 4,062 & 0,464 \\
e1 & $<-->$ & e7 & 4,737 & 0,542 \\
\hline \multicolumn{2}{c}{ Sumber $:$ Hasil Pengolahan Data Penelitian $(2015)$} &
\end{tabular}

Model tersebut kemudian dimodifikasi mengikuti modification indicies, modifikasi dilakukan beberapa kali dengan tujuan untuk memperoleh nilai yang sesuai dengan nilai acuan persamaan model struktural, berikut ini rincian tahap modifikasi yang dilakukan : Tahap pertama, Menghubungkan error pengukuran (e10) dari Kepuasan Pelanggan dengan (e11) dari Word Of Mouth. Tahap kedua, Menghubungkan error pengukuran (e9) dari Kepuasan Pelanggan dengan (e11) dari Word Of Mouth. Tahap ketiga, Menghubungkan error pengukuran (e3) dari Brand Image dengan (e13) dari Word Of Mouth. Tahap keempat, Menghubungkan error pengukuran (e2) dari Brand Image dengan (e13) dari Word Of Mouth. Tahap kelima, Menghubungkan error pengukuran (e2) dari Brand Image dengan (e4) dari Word Of Mouth. Tahap keenam, Menghubungkan Brand Image (X1) dengan Service Quality (X2).

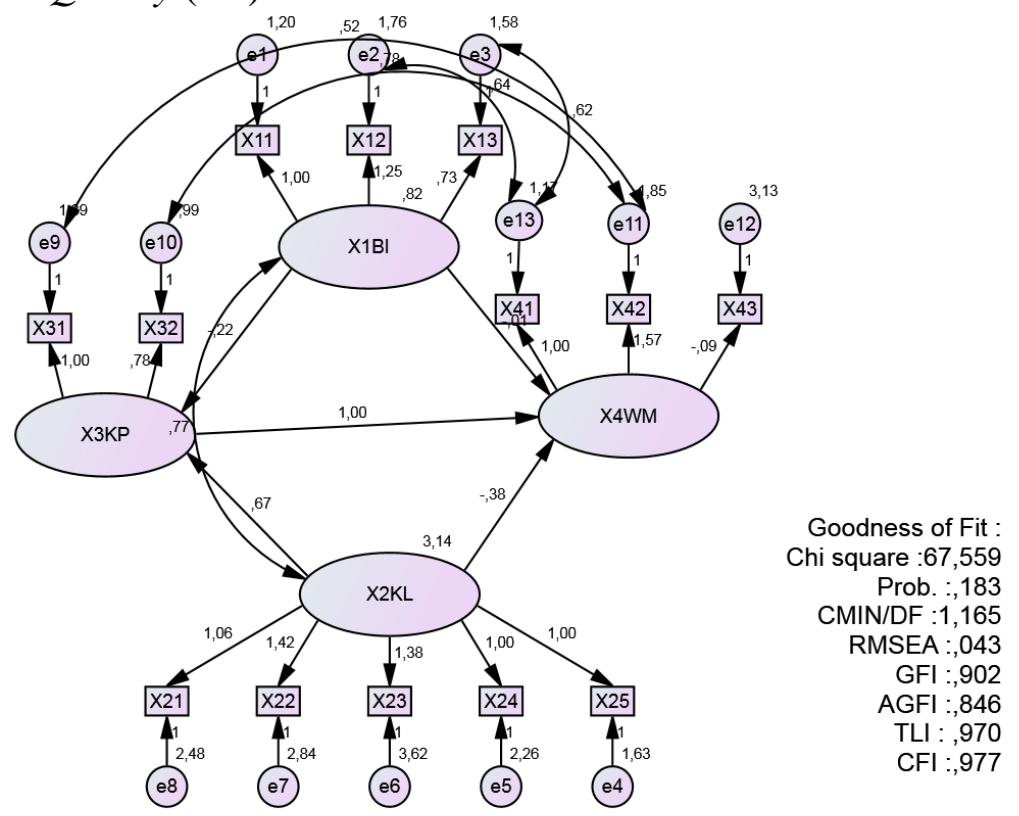

Gambar 1.3 Modifikasi Model

Sumber : Hasil Pengolahan Data Penelitian (2015)

Hasil uji kesesuain model menggunakan chi - square, CMIN/ DF, GFI, AGFI , RMSEA, TLI dan CFI setelah dilakukan modifikasi adalah sebagai berikut:

Tabel 1.10. Hasil goodness of fit Setelah Modifikasi 


\begin{tabular}{llll}
\hline \multicolumn{1}{c}{ Indeks } & \multicolumn{1}{c}{ Cut off Value } & \multicolumn{1}{c}{ Hasil } & Evaluasi model \\
\hline chi-square & Sekecil mungkin & 67.559 & Marginal \\
Probability & $\geq 0.05$ & 0.183 & Baik \\
CMIN/ DF & $\leq 2.00$ & 1.165 & Baik \\
RMSEA & $\leq 0.08$ & 0.043 & Baik \\
GFI & Mendekati 1 & 0.902 & Baik \\
AGFI & Mendekati 1 & 0.846 & Cukup \\
TLI & Mendekati 1 & 0.970 & Baik \\
CFI & Mendekati 1 & 0.977 & Baik \\
\hline
\end{tabular}

Sumber : Hasil Pengolahan Data Penelitian (2015)

Tabel 5.14. Menunjukkan bahwa model yang direncanakan fit secara baik, karena setelah diuji kecocokannya nilai chi - square , Probability, CMIN/ DF, GFI, AGFI , RMSEA, TLI dan CFI hasilnya baik.

Hubungan antar variabel dengan tingkat signifikansi dibawah 0,05 menunjukkan bahwa hubungan tersebut adalah hubungan yang signifikan. Pada studi ini diajukan 5 (Lima) hipotesis yang selanjutnya pembahasan atas hasil pengujian hipotesis adalah sebagai berikut :

Tabel 1.11. Hasil Pengujian Hipotesis

\begin{tabular}{|c|c|c|c|c|c|c|c|c|}
\hline & & & $\begin{array}{c}\text { Std. } \\
\text { Estimate }\end{array}$ & Estimate & S.E. & C.R. & $P$ & Keterangan \\
\hline $\begin{array}{l}\text { Kepuasan } \\
\text { Pelanggan }\end{array}$ & $<--$ & $\begin{array}{c}\text { Citra } \\
\text { Merek }\end{array}$ & 0,333 & 0,5 & 0,233 & 2,144 & 0,032 & Signifikan \\
\hline $\begin{array}{r}\text { Kepuasan } \\
\text { Pelanggan }\end{array}$ & $<--$ & $\begin{array}{l}\text { Kualitas } \\
\text { Pelayanan }\end{array}$ & 0,749 & 0,483 & 0,118 & 4,085 & $* * *$ & Signifikan \\
\hline $\begin{array}{l}\text { Word Of } \\
\text { Mouth }\end{array}$ & $<--$ & $\begin{array}{c}\text { Citra } \\
\text { Merek }\end{array}$ & 1,593 & 1,68 & 0,69 & 2,434 & $\mathbf{0 , 0 2}$ & Signifikan \\
\hline $\begin{array}{l}\text { Word Of } \\
\text { Mouth }\end{array}$ & $<--$ & $\begin{array}{l}\text { Kualitas } \\
\text { Pelayanan }\end{array}$ & 6,856 & 2,283 & 1,05 & 2,174 & $\mathbf{0 , 0 3}$ & Signifikan \\
\hline $\begin{array}{l}\text { Word Of } \\
\text { Mouth }\end{array}$ & $<--$ & $\begin{array}{c}\text { Kepuasaan } \\
\text { Pelanggan }\end{array}$ & 7,033 & 2,682 & 1,045 & 2,567 & 0,01 & Signifikan \\
\hline
\end{tabular}

Sumber : Hasil Pengolahan Data Penelitian (2015)

Hal ini menunjukkan bahwa keseluruhan hipotesis pada penelitian ini berpengaruh positif dan signifikan. Dimana Hubungan antar variabel dengan tingkat signifikansi dibawah 0,05 menunjukkan bahwa hubungan tersebut adalah hubungan yang signifikan. sehingga dengan demikian ke 5 hipotesis penelitian dapat diterima.

Agar dapat diberikan sarang yang lebih operasional, dilakukan pengujian hubungan antar dimensi variabel bebas dengan dimensi variable terikat. variable Kualitas Pelayanan, dimensi yang paling kuat hubungannya adalah Dimensi Empati (Empathy) terhadap Dimensi Harapan pada variabel Kepuasaan Mahasiswa karena memiliki nilai koefisien = 0.573 ini dimaksudkan bahwa dimensi kualitas pelayanan dalam dimensi empati berkaitan dengan harapan mahasiswa. Ini menunjukan bahwa empaty yang diberikan kepada mahasiswa dapat menjadi harapannya pelanggan.

Brand Image Terhadap Kepuasan Pelanggan memiliki pengaruh yang signifikan terhadap kepuasan pelanggan hal ini sesuai dalam penelitian Young (2012) yang menyatakan bahwa Brand Image berkaitan dengan Kepuasan Pelanggan. Hal ini terjadi karena brand image yang dibuat oleh universitas mercu buana menjadi bagian terhadap kepuasan pelanggannya yakni mahasiswa sebagai pengguna jasa pendidikannya. Pengaruh Service Quality Terhadap Kepuasan Pelanggan memiliki pengaruh positif dan signifikan terhadap kepuasan pelanggan. Hal ini sesuai dengan penelitian Indra (2011). Ini terjadi karena UMB memiliki orientasi untuk terus meningkatkan mutu pendidikan dan pelayanan yang ada. 
Brand Image terhadap Word Of Mouth, berpengaruh positif dan signifikan terhadap Word Of Mouth. Hal ini sesuai dengan penelitian Chaniotakis (2009), yang menyatakan bahwa Brand Image berpengaruh signifikan terhadap WOM. Brand Image yang dibangun oleh Universitas Mercu Buana membuat para pengguna jasanya melakukan WOM positif dimana bisa dilihat dari hasil uji korelasi antar dimensi bahwa Brand Image memberikan nilai tinggi terhadap rekomendasi WOM sehingga memiliki hubungan yang kuat. Pengaruh Service Quality terhadap Word Of Mouth, berpengaruh positif dan signifikan terhadap Word Of Mouth. Hal ini sesuai dengan penelitian Chaniotakis (2009), yang menyatakan bahwa Service Quality berpengaruh signifikan terhadap WOM. Service Quality yang sangat prima ditunjukan oleh Universitas Mercu Buana membuat para pengguna jasanya melakukan WOM positif sehingga memiliki hubungan yang kuat.

Pengaruh Kepuasan Pelanggan terhadap Word Of Mouth, berpengaruh positif antara Kepuasaan Pelanggan dan Word Of Mouth. Dalam hal ini Kepuasan Pelanggan yakni mahasiswa mercu buana jika merasa puas dapat memberikan saran, rekomendasi dan referensi kepada orang lain begitu sebaliknya.

\section{PENUTUP}

Berdasarkan uraian pada bab-bab sebelumnya, maka berikut ini adalah kesimpulan yang dapat penulis kemukakan dalam penelitian ini :

1) Hasil penelitian menunjukan bahwa faktor brand image berpengaruh positif dan signifikan terhadap kepuasan.

2) Hasil penelitian menunjukan bahwa faktor service quality berpengaruh positif dan signifikan terhadap kepuasan.

3) Hasil penelitian menunjukan bahwa faktor brand image berpengaruh positif dan signifikan terhadap word of mouth.

4) Hasil penelitian menunjukan bahwa faktor service quality pasti berpengaruh positif dan signifikan terhadap word of mouth.

5) Hasil penelitian menunjukan bahwa faktor kepuasan berpengaruh positif dan signifikan terhadap word of mouth.

Berdasarkan kesimpulan tersebut, penulis memberikan saran pada manajemen universitas mercu buana dengan tujuan untuk peningkatan jumlah mahasiswa baru sebagai berikut :

1. Baiknya manajemen mampu mengendalikan informasi informasi yang keluar secara negatif di media massa. Dalam kualitas pelayanan bukti fisik baiknya pihak manejemen kampus terus memonitoring infrastruktur dan kebersihan lingkungannya. Dalam keandalan baiknya sering melakukan training terhadap karyawan yang sering bertemu dengan mahasiswa sehingga kemampuan mereka dalam melayani dapat diandalkan secara maksimal.

2. Manajemen kampus harus selalu berusaha memberikan kepuasan bagi mahasiswanya, memberikan sebuah kepuasaan kepada pelanggan merupakan tugas berat bagi manajemen. Agar mahasiswa dapat memberikan word of mouth positif kepada lingkungan sekitar. Melihat dari hubungan yang ada antara kepuasan terhadap word of mouth, hanya terjadi pada rekomendasi yang dinilai lumayan baik. Oleh karena itu baiknya Member Get Student untuk mahasiswa reguler di buka kembali karena ini dapat memacu mahasiswa untuk merekomendasikan orang lain. 


\section{DAFTAR PUSTAKA}

Arikunto, S. (2010). Prosedur Penelitian Suatu pendekatan Praktik. Jakarta: Rineka Cipta.

Aryani, D dan Rosinta, F. (2010). Pengaruh Kualitas Layanan Terhadap Kepuasan Pelanggan Dalam Membentuk Loyalitas Pelanggan. Jurnal Ilmu Administrasi dan Organisasi. Vol.17. No.2.

Babin, Barry J., Yong-Ki Lee, Eun-Jun Kim and Mitch Griffin. (2005). Modeling Consumer Satisfaction and Word of Mouth : Restaurant Patronage in Korea. Journal of Service Marketing, 19, pp. 133-139., Journal of Consumer Research, Vol. 20, No. 4, pp 644-656.

Brown, Barry, Dacin and Gunst. (2005). Spearching for a consensus on the antecendent role of service quality and satisfaction: an exploratory cross-national study. Journal of Business Research, Vol. 51.pp. 53-60.

Ferdinand, Agusty. (2000). Structural Equation Modeling Dalam Penelitian Manajemen. Semarang : BP UNDIP.

Harrison, L. Jean-Walker. (2001). The Measurement Of Word Of Mouth Communication And An Investigation Of Service Quality And Customer Commitment As Potential Antecedents. Journal of Service Research, Vol. 4, No. 1, pp. 60-75.

Hawkins, D. I., D. L. Mothersbaugh., dan R. J. Best. (2007). Consumer Behavior : Building Marketing Strategy. Tenth Edition. McGraw-Hill. New York, USA.

Kotler, Philip. (2004). Manajemen Pemasaran. Edisi Millennium (Terjemahan). Jakarta: Prenhallindo.

(2005). Marketing management, 10th edition. Upper Saddle River: Prentice Hall, Inc.

Kotler, Philip and Keller, Kevin Lane. 2006. Marketing Management. Twelfth Edition. New Jersey : Upper Saddle River ISSN 1410-4628

. (2008). Manajemen Pemasaran. Edisi Kedua Belas Jilid I \& II. PT. Indeks, PT Mancana Jaya Cemerlang, Jakarta.

(2009). Marketing Management. 14 Edition Pearson International, New Jersey : Prentice Hall.

. (2012). Marketing Management. Fourteenth Global Edition. Pearson Education.

Lo Liang Kheng, Osman Mahamad, T. Ramayah and Rahim Mosahab. (2010). The Impact of Service Quality on Customer Loyalty : A Study of Banks in Penang, Malaysia. International Journal of Marketing Studies, Vol. 2, No. 2.

Lori K. Molinari, Russell Abratt, Paul Dion. (2014). Satisfaction, quality and value and effects on repurchase and positive word-of-mouth behavioral intentions in a B2B services context. International Journal of Marketing Studies, Vol. 2.

Lovelock, Christoper \& Jochen Wirtz. (2007). Manajemen Pemasaran Jasa. Jakarta : Indeks.

Malhotra, N. K. (2005). Riset Pemasaran Jilid I dan II (Edisi Bahasa Indonesia dari Marketing Research: An Applied Orientation 4e). PT. Intan Sejati, Klaten.

Mansur, Ahmad. (2009). Diktat Metode Penelitian Dan Teknik Penulisan Laporan. Universitas Padjajaran. Bandung.

Rahim Mosahab, Osman Mahamad and T. Ramayah. (2010). Service Quality,Customer Satisfaction and Loyalty: A Test of Mediation, International Bussiness Research, Vol. 3, No. 4.

Rosiana Desak Gede. (2011). "Pengaruh E-Servqual Terhadap Nilai Pelanggan, Kepuasan dan Word of Mouth Communication Anggota Situs Jejaring Sosial Facebook", Tesis, Program Studi Magister Manajemen Fakultas Ekonomi Universitas Udayana, Denpasar. 
Schiffman, L.G., Kanuk, L.L. (2008). Perilaku Konsumen. Edisi Ketujuh. PT Indeks, Jakarta.

Sopiah dan Syihabuddin. (2008). Metode Penelitian Bisnis. Yogyakarta : Andi.

Sugiyono. (2008). Metode Penelitian Bisnis. CV Alfabeta, Bandung.

. 2012. Metode Penelitian Kuantitatif Kualitatif dan R\&D. Alfabeta. Bandung.

Suprapti, N. W. S. (2010). Perilaku Konsumen : Pemahaman Dasar dan Aplikasinya Dalam Strategi Pemasaran. Udayana University Press. Denpasar.

Tjiptono, Fandi. (2006). Strategi Pemasaran. Jakarta : Gramedia.

(2008). Strategi Pemasaran. Edisi ketiga. Yogyakarta: Penerbit Andi Ofset.

Tjiptono, Fandi dan Chandra, Gregorius. (2011). Service Quality and Satisfaction Edisi3, Jakarta : Andi.

Umar, Husein. (2005). Penelitian Pemasaran dan Perilaku Konsumen. Jakarta : PT Gramedia Pustaka Utama.

You- Ming, Chou. (2010). Study on The Impacts of Experiential Marketing and Customer Satisfaction Based on Relationship Marketing. International Journal of Organizational Innovation (Online), vol 3, 189-209.

Young Ha, Hyunjoo Im. (2012). Role of web site design quality in satisfaction and word of mouth generation. Journal of Service Management, 23(1):h:79 - 96. 